\title{
The Impact Dimensions of Service Quality on the Acceptance Usage of Internet Banking Information Systems
}

\author{
Laith T. Khrais \\ Department of Business Administration, College of Applied Studies and Community Services, \\ Imam Abdulrahman Bin Faisal University, P.O. Box 1982, Dammam, Saudi Arabia
}

Article history

Received: 16-09-2017

Revised: $10-02-2018$

Accepted: 05-04-2018

Email: Laithkh82@hotmail.com

\begin{abstract}
Nowadays, banking transactions are one of the most important daily services that fulfill a society needs. The broadly growth of information technology usage pushed banking institutions to embrace advanced technology to launch new electronic services. Internet technology has influenced the banking practicability because of its capability to enhance performance of financial operations. A major concern of Internet banking systems is the customers' perception of service quality that render Internet banking a unique environment due to the lack of physical interaction between bank personnel and the customer. Thus, there is a necessity need for banking institutions identify factors that convince customers and raise their intention towards usage of these services. The purpose of this paper is to set forth a valid means and contribute to the field of measuring online service quality with a focus on optimizing this perception via electronic transactions in the domain technology of the banking industry and its reliability by examining the most important factors affecting customer perception towards acceptance of Internet banking in Jordan. The conceptual framework formulated and developed in this research study is an extension to the Technology Acceptance Model (TAM). The model was tested with a survey sample of 500 banking customers chosen randomly. The findings of the study indicate that all mentioned factors in the hypothesized model (TR, SP, QI, AW, PU and PEU) have significant impact within creating a positive atmosphere for stimulating the acceptance and use of Internet banking systems. Data analysis is based on the Statistical Package for Social Science (SPSS).
\end{abstract}

Keyword: Adoption Factors, Internet Banking, Technology Acceptance Model (TAM), Online Services, Jordan

\section{Introduction}

In the past, firms had usually used digital computers to manage their routine operations. Now, however, advances in technology and information systems have enabled firms to streamline their transactions with suppliers, distributors and customers through the electronic exchange of information. Consequently, many firms are embracing online business, as a means of enlarging markets, enhancing productivity and reducing costs to improve customer service widely. Due to the recent witnessed development of information systems which intensively transformed the rules for all different industry practices, including the banking sector to digital systems to prompt the idea of Internet banking.

Competitive banking institutions actively adapt to their changing environments. With the passage of time and the advent of technology, the size of an organization's business must increase to gain recognition and profit. Today, banking sector firms are becoming more competing than before to increase their profit of market share. As through the adoption of advanced technologies have enabled banks to extend their customer base, where Internet banking has proved to be the future of new services in the digital era.

The diffusion of the Internet has obviously had a transformational effect overall society. It has opened a 
new medium of communication for firms to communicate and get information in an entirely different way. The Internet can currently be considered as the cheapest distribution channel for standardized bank operations, such as account services or transfer of funds (Polasik and Wisniewski, 2009). In their study of Turkish online banking, Polatoglu and Ekin (2001) reported that the average cost of online transactions was $\$ 0.10$, compared to $\$ 2.1$ for a teller. Additionally, a study of Natarajan et al. (2010) argued that Internet banking has substantial advantages in terms of usefulness and purpose and as such, it attracts customers to use online banking services.From the viewpoint of the consumers, the decision to use Internet banking is frequently motivated by convenience and efficiency (Bruno, 2003), thus helps consumers in conducting fast and convenient financial transaction activities.

Since that banking industry is one of the major users of information and communication technologies in business life (Khrais and Abdalkrim, 2013), the new economic era has opened a new paradigm of globalization, liberalization and advanced technology revolution for banking institutions to create digital value of innovative services in the electronic financial domain across the globe. However, people can access Internet banking via computers and mobile devices (smartphones) connected to the Internet.Moreover, the benefits of selfservice technologies are urged to stem from the fact that customers can access services when and where they want without some of the complications of interpersonal exchanges (Bitner et al., 2000). Internet banking system is a vital example of such advanced technologies and forms the main axis in this current study.

The Middle East region (ME), including Jordan, has recently witnessed significant financial, economic and technological development changes. Commercial banks in ME are dominated a large size of the capital market structure. The reputation of Jordan is growing as a center of financial attractive in the Middle East region is reflected by the increase of financial institutions registered that providing a variety of new banking services. Jordan has a successfully growing economy as its telecommunication industry has advanced tremendously in the recent years. The Central Bank of Jordan was launched a program so called (E-fawateercom) since 2015. It is a digital system for displaying and collecting invoices electronically. With this system Individual will be able to choose the right payment channel through the various payment channels, which include online banking, telephone, ATM, Jordanian post offices and from various accredited centers such as Carrefour and others. This system has various benefits such as reduce the time, money and effort of paying bills compared to the traditional way.
According to the latest statistics, the number of Internet users is estimated at about 7 billion and half across the world at the end of 2017. Further statistics clarify the total number of Internet users in Jordan is estimated to be $6,300,000$, with $80 \%$ of the Internet penetration among the whole population of Jordan (IWS, 2017). This result obviously demonstrates that telecommunication and Internet sector is one of the fastest growing industries in Jordan. Despite of studies that discover the service quality of Internet banking technology are obtainable, in the same time, there are deficient studies of Jordanian context. Therefore, the motivations for this research is to develop and test a new theoretical model to provide more reliable source of information for the banking sector.

The main objective of this study is to investigate the direction effects of service quality dimensions on the acceptance of Internet banking by developing an Internet banking system model (for community in Jordan), that boosts their intentions to embrace this technology. To achieve this objective, the author proposes the research question as follows: "What factors affect the acceptance of using the Internet banking from the user's perception of service quality?". The remainder of the paper consists of the following sections: The next section presents an overview of literature review and Internet banking workflow. The next section presents a research methodology that includes the model development, experiment design and implementation followed by findings discussion, conclusions and future considerations.

\section{A Workflow of Internet Banking System}

The rapid development of information and communications technology has obviously increased the competition between financial institutions through innovative strategies affected the industry of Internet banking and its service quality. The volume of digital transaction has witnessed exponential growth in volume and value whether it is digital wallet, interbank transfer or transaction by debit or credit card. The development and diffusion of Internet banking technology are expected to result in more efficient banking systems. Therefore, the acceptance of online banking services has been rapid in many parts of the world and banks that do not offer fully online services are expected to lose more of their customers over the next years. According to (Khrais and Abdalkrim, 2013), there are four basic services for online banking systems:

- View account balance with transaction history

- Paying bills, traffic violation and residence fees

- Transferring funds between accounts (locally and globally)

- Online purchasing and request credit card advance 


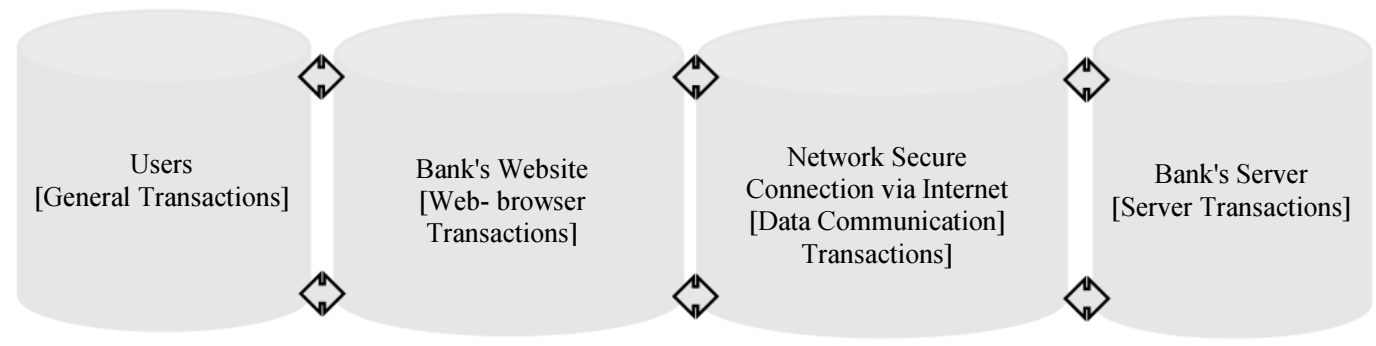

Fig. 1: Online banking system workflow

Internet banking system is an innovative form of advanced technology with a series of set processes that the clients $\log$ s into the bank's website through the web-browser installed on the PC and carries out various online transactions by using a private username and password based on the user's selection (Laith, 2015). He added that online banking system is carried out in four main phases:

- The user runs on the installed operating system

- After the web-browser opened, users can access the bank's website and then enters the Personal Identifying Number (PIN) and the password by using the keyboard

- The data input is encrypted by Secure Socket Layer (SSL) and transmitted to the bank's server

- The bank's server decrypts the transmitted information and processes of the user's authentication

Notably, banks create their formal web site through the adoption of basic web technologies. Interaction between user and service provider systems is supported by multilevel dialogs. The bank account server as part of the system receives the instructions to provide the substantial functions to be performed on the bank accounts, whereby end users assume more responsibility for their own applications and they rarely have direct interaction with the operations staff of the websites. A study by Laith (2015) clarified the main functional components, their roles and contribution within the entire system, whereby the end-user can access the secure website of the bank via the Internet, as shown in Fig. 1.

From the viewpoint of financial institutions, the phenomenon of Internet banking assures the exploitation of new business opportunities in the banking domain in terms of more effective performance, greater economic efficiency and a quicker exchange among financial markets and that is through supports communication with other servers, such as Internet information servers. These participate in the environment and contribute other services and information to present a variety of online services.
The next section presents the development of the theoretical framework model.

\section{Development of the Theoretical Model}

The banking industry is constantly driven by new technological innovation, market uncertainty and intense competition. Therefore, the management structure of banking institutions plays a pivotal role in new technology service adoption. There has been a rapid shift from traditional banking to Internet banking due to adopting the latest technology to align business strategies, enable innovative, functional operations and present extended new services. Undoubtedly that the acceptance of both the Internet technology and online service providers is the drive essential adoption of Internet banking services.

Many researchers used different approaches or theories to predict and test the determinant factors that affect users' acceptance of information technology systems, including the theory of reasoned action (TRA) (Ajzen and Fishbein, 1980), the Theory of Planned Behaviour (TPB) (Mathieson, 1991), the model of PC utilization (Thompson et al., 1991), the decomposed theory of planned behaviour (Taylor and Todd, 1995; Tan and Teo, 2000), innovation diffusion theory (Rogers, 1993; Agarwal and Prasad, 1999) and the moguls model of computing (Ndubisi et al., 2004). Nevertheless, the Technology Acceptance Model (TAM) was one of many theories that have helped in providing theoretical framework for research in the adoption of using information technology over decades due to its popularity with high credibility. In this context, (TAM) is applied in this current study as a theoretical background for some reasons:

- It is the most effective model in the field of information systems and technology for testing user acceptance and usage behaviour (O'Cass and Fenech, 2003)

- It has a predictive power which makes it easy to apply in different situations (Venkatesh and Morris, 2000)

- There is a common agreement among researchers that the model is useful in predicting individual's 
acceptance of various technologies (Adams et al., 1992; Doll and Torkzadeh, 1998)

Since the introduction of TAM, many studies have applied it in a broad variety of IT applications to predict user acceptance behaviours of computer technologies. Many researchers suggest that additional variables in TAM are required to derive a better understanding of determinant factors influencing the decision of bank users to use Internet banking systems. As proposed by Davis (1989), the TAM depicts that perceived usefulness and perceived ease of use determines an individual's intention to use a system and he added that research in technology acceptance must be addressed, how the other variables effect of usefulness, ease of use. Numerous studies have sought to expand the TAM by incorporating additional constructs (Taylor and Todd, 1995). Moreover, Moon and Kim (2001) suggested that to increase the external validity of TAM, it is necessary to further explore the nature and specific influences of technology and usage context factors that may alter the user's acceptance. Therefore, perceived ease of use and perceived usefulness are not fully enough, necessitating a discover for additional factors that can better predict the acceptance of Internet banking.

In the current study, the researcher defines technology innovation as bridges to fit the gap between customer's expectation and their perceived experience of performance. Thus, the technology advancement increases the usefulness that leads to satisfying more users. In this context, this study proposes an extended version of the Technology Acceptance Model (TAM) modified by the researcher to determine the essential factors of service quality affecting customer perception towards the phenomenon of Internet banking acceptance in Jordan. The proposed variables were verified and tested to ensure the appropriate meanings. Thus, several hypotheses have been erected for examining the theoretical model in Jordan.

\section{Trust (TR)}

Trust is basically an essential element for any social and business relationships. Trust has been considered a decisive factor in stimulating purchases over the Internet (Quelch and Klein, 1996; Jarvenpaa et al., 2000; Stewart, 2003; Kim and Kim, 2005). Gefen et al. (2003) defined trust as the expectations that other individuals or companies with which one interacts will not take improper advantage resulting from the dependence one has on them. A study by Khalil and Pearson (2007) emphasized that the trust significantly influences the attitude towards Internet banking acceptance. In this current study, the researcher defines trust as an exchange the reliability between two parties within uncertain online activities, as through identifying its dimensions such as trusted transactions, reading data on the website concerning a bank's legal compliance, offer of guarantees, exploiting brand reputation and reading customers' comments. Therefore, it is hypothesized that:H1:Trust (TR) has a positive impact on the customer's perceived usefulness toward acceptance of Internet banking.

\section{Security and Privacy (SP)}

In general, people show more concern about the use of banking services when the money became insecure. Numerous researchers (Mzoughi et al., 2007; Lee, 2009) debated consumer concerns about security and privacy. Perceived risk is a major part of consumers' Internet banking decision-making process. The reason for such importance lies in the fact that, in the absence of any practical guarantee, the consumer cannot be certain that the bank will not resort to undesirable, opportunistic behavior, such as the violation of privacy, unauthorized use of credit card information, inequitable pricing or access to unauthorized transactions (Reichheld and Schefter, 2000).

Some customers are afraid that they may make mistakes in their banking transactions when using a computer (Kuisma et al., 2007; Laukkanen et al., 2009). Additionally, it has also been reported that some bank customers fear hackers, who may access their bank accounts illegally (Poon, 2008). Thus, customers will be affected by the case of insecurity and concern about the privacy and control of their personal information. According to Laith (2015), the attack strategies and techniques can be divided into three main vectors that can be used against online banking systems, such as:

- Firstly, a credential stealing attack (CSA), is where fraudsters try to gather users' credentials, either with the use of a malicious software or through phishing

- Secondly, a Channel Breaking Attack (CBA), involves intercepting the communication between the client side and the banking server, by masquerading as the server to the client and vice versa

- Thirdly, a content manipulation also called Man-inThe Browser (MiTB) attack; it takes place in the application layer between the user and the browser. The adversary is granted with privileges to read, write, change and delete browser's data whilst the user is unaware about it

It therefore must protect the end users of online banking with multi-faceted security solutions that understands all the trends of hacking and gathering all the technologies that can ensure security for end 
user's data input, security for web browsing and security for the connection network used (Laith, 2015). He also suggested that the models adopted in online banking systems are based on several layers of security, consist of multi solutions and mechanisms which aim at protecting the online banking applications and the user's data in the whole process, such as: Digital certificates, One-Time Password (OTP) tokens, Short message service (SMS), OneTime Password (OTP) cards, Browser protection, Device register Device identification, Pass-phrase, Positive identification and lastly Biometric authentication technology. Additionally, it is maintained that security protection systems have a significant effect on perceived trust (McKnight et al., 2004; Grewal et al., 2004; Kimery and McCord, 2006).

Banks should be planning to offer services that would protect customers against fraud arising from the misrepresentation of identities. Different studies assured that consumers who feel safer with the Internet are more likely to trust a certain website (Gefen et al., 2003). A study of Wakefield and Whitten (2006) maintained that security organizations could generate more trust for certain electronic traders, such as those offering banking services over the Internet. The transaction risk excludes when the banking institution's success to deliver adequate privacy and secure online services to increase the trust of using Internet banking. As to support the statement, Mukhtar (2015) states that security in online banking services is important factor to change customers' perception on internet banking from negative to positive. For this reason, the researcher therefore hypothesized that H2: Security and Privacy (SP) have a positive impact on the customer's trust toward acceptance of Internet banking.

\section{Awareness of Services $(A W)$}

Gaining awareness is essentially influential for using Internet banking benefits and that this must be achieved correctly (Laith, 2017). According to Sathye (1999) and Al-Somali et al. (2009), awareness of the service has direct influence on user intention to use the technology. They added that low level of awareness is a critical factor in causing customers not to adopt online banking. H3: Awareness of online services (AW) and its benefits has a positive impact on the customer's perceived ease of use toward the acceptance of Internet banking.

\section{Quality of Internet (QI)}

The quality of the Internet connection is a major ingredient for any web-based applications (Laith, 2017). With improper Internet connection, the use of Internet banking becomes impossible. The researcher assigns QI in the context of Internet banking as the ability to guarantee a certain level of data flow performance to lower customers' concerns about the connection quality and the possibility of a poor connection constituting a risk to banking transactions. Thus, confirms that there is a significant relationship between the speed of the Internet and the use of Internet banking services. H4: Perceived quality of the Internet connection (QI) has a positive impact on the customer's perceived usefulness toward the acceptance of Internet banking.

\section{Perceived usefulness (PU)}

(PU) is one of the most popular and important factors in the existing literature of online banking system (Guriting and Ndubisi, 2006; Jaruwachirathanakul and Fink, 2015). This importance of PU suggests that users are generally more likely to accept a system primarily because of the functions it performs, implying that the ease of use cannot compensate for a system that does not provide the required functionality (Davis, 1989). A study of Al-Somali et al. (2009) showed that perceived usefulness influence customer interactions with Internet banking and they suggested that perceived usefulness affects the adoption of Internet banking services. In this context, the researcher assigns PU in the context of Internet banking as the degree to which a user believes that using Internet banking system service would enhance banking services usability. H5: Perceived usefulness has a significant positive effect on the intention to use the Internet banking system.

\section{Perceived Ease of Use (PEU)}

This study suggests that the Internet banking system requires less effort to use, learn and train. Thus, the researcher determines PEU as the degree to which a user believes that using Internet banking technology would be free from effort. An empirical study conducted by Wang et al. (2003) shows that perceived ease of use has a direct significant positive effect on behavioral intention to use Internet banking. Gefen et al. (2003) further point out that perceived ease of use, trust and perceived usefulness are considered as significant determinants of online shopping. Based on TAM, a direct positive relationship has existed between PEU and PU and that leads to improved performance by saving effort needed to do the same work, which is proved by the increase in PEU (Davis, 1989; Adams et al., 1992; Venkatesh and Davis, 2000). Therefore, a new hypothesis is added:

H6a: Perceived ease of use has a positive impact on the intention to use the Internet banking system.

H6b: Perceived ease of use has a positive impact on the user's perceived usefulness of the Internet banking system. 


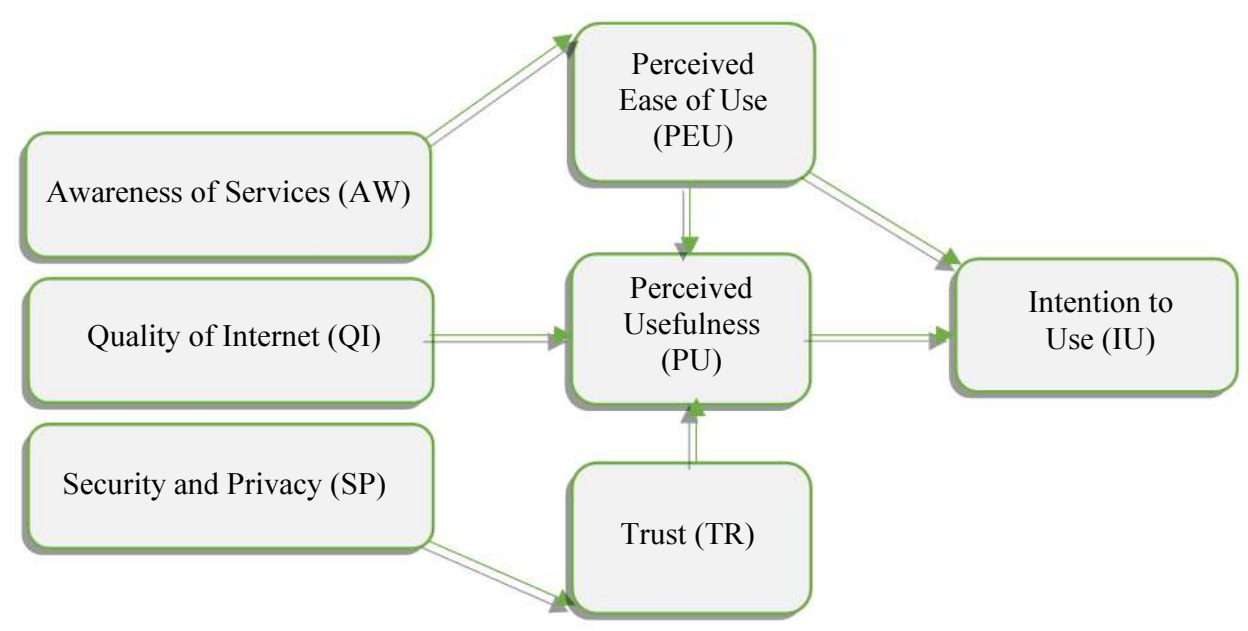

Fig. 2: The proposed model

Furthermore, drawing on the relevant of previous researches conducted with TAM in predicting new acceptance technology, actual usage is often measured through Behavioral Intention (BI) (Davis, 1989; Jarvenpaa et al., 2000; Shih, 2004; Gumussoy and Calisir, 2009; Saleh and Steve, 2014) and therefore determines technology acceptance. Thus, it is theoretically justified to go along with previous studies to adopt the intention to use (IU) as an ultimate independent variable to test the framework of this study. According to Fig. 2 exemplifies the proposed model which forms the basis for further empirical analysis. It divides the dimensions of service quality which were hypothesized to influence the process of Internet banking acceptance.

\section{Research Method}

Having reviewed the literature and formulated the research hypotheses, the researcher now presents the specific methodology developed for the main study on the effect of factors generate in the research model. A research design is a plan, structure and strategy to obtain results of the main aim of the research study.

To achieve the purpose of the study, the researcher consistent with most of the studies undertaken in this domain to adopt a quantitative study in seeking respondents' opinions. A survey questionnaire was formed based on literatures and information systems studies and then developed for testing hypotheses. Interval scaling in the form of a numerical scale was selected as the most appropriate to measure all variables of the study. In this scale, numbers are assigned to indicate order and measure distance in units of equal intervals (Zikmund, 2003). The Likert scale is accepted and treated as yielding interval data by most of researchers (Coldwell and Herbst, 2004). In this line, the study employed Likert-type scale questions. Each question could be answered by selecting 1 -strongly disagree to 5 -strongly agree, so in order to examine participants' responses about nature main factors that formed the proposed model.

While it is difficult to get responses from a whole population, this research employs an online survey for data collection in term of its benefits in saving time and expenses for researcher. A pop-up window with an invitation to participate in the survey was displayed to participants and further explained the purpose of this study to ensure confidentiality and privacy of the data collection process (Laith, 2017). Of the 500 surveys randomly distributed in the Jordanian community o obtain an enough required sample size. Four hundred and twenty-five usable responses were collected after the screening, yielding a response rate $85 \%$. All respondents were bank customers with the expected age of 18 years or older.

According to a survey, the questionnaire is split into three main sections. It initiates with the demographic section, which consist of questions that gather information about gender, age, level of education and income. The second section requested participants to provide background information on Internet usage. The last section contained items of different constructs in the hypothesized model to measure the study variables. Closed-ended questions were used in the survey to keep the context of the question same for all respondents (Frazer and Lawley, 2000) to lessen bias.

Participation was voluntary and data was collected anonymously. This study did not involve personal information about subjects. The introductory page explained the aims of the study purpose and invited each 
receiver to participate in the survey. Their right to withdraw at any time during the survey was explicitly stated. Further, data collected from this research has been kept confidential. The next section presents the findings of the analysis.

\section{Results and Discussion}

The proposed hypotheses were examined within an online survey involving 425 banking customers residing in Jordan. Accordingly, the data model was refined through validation of the principal component analyses of hypothesized structure model statistically. A collected quantitative data was analyzed using selected tools of Statistical Package for Social Sciences (SPSS) to test and interpret the results of the data analysis. For instance, the descriptive statistics of the respondents' demographic characteristics were analyzed and presented first in Table 1 as shown below and then extract of other hypothesis analysis are presented next.

The empirical results suggest that the proportions of Internet banking usage were partially close for both genders, 47 percent of the respondents were female and the largest proportions (53\%) of respondents were male. The largest proportion of constituting the dominant age category for young people 18-35 was (71\%). Moreover, the survey respondents were generally well educated with (53\%) holding bachelor degree and (29\%) having postgraduate qualifications. This point out that all respondents have an education level sufficient to provide precise answers to the questionnaire. Based on the income, the largest proportion (45\%) of respondents, were those earn 500-1000 JD monthly. The results also reveal that all subsamples use the Internet service with the largest proportion (99\%) for 5 years of experience and more regardless of the nature location whether at home or workplace. Moreover, the findings also reveal that participants of this study generally have an exexperience of using Internet banking systems. This indicates that they are better prepared to provide accurate answers to serve the main purpose of the study.

In addition, reliability assessment was conducted to evaluate the Cronbach's Alpha values for all items in the measure. All the measures used in the current study show an adequate reliability with Cronbach's alpha values ranging between (71 and 84\%), which beyond the barrier of $(70 \%)$ as the lower limit of acceptability (Sekaran, 2000). This ensures that the items grouping of the respective variables are reliable and well-designed under the conditions of this survey. After examining the reliability of the measurement model, the next step was to assess the proposed theoretical model.

\section{Relationship Testing}

In line with the study objective, regression analysis was used to determine how the predictor variables could explain the dependent variable and therefore to empirically decide whether to accept hypotheses or not. Given that multicollinearity between latent variables might have a small but significant impact on the bias of path coefficients (Kristensen and Eskildsen, 2010), the author checked for potential multicollinearity among independent variables. A collinearity test revealed minimal collinearity with the Variance Inflation Factor (VIF) of all constructs ranging between 1.184 and 3.354. As a rule of thumb, it is most often recommended that the VIF value should be lower than 10 .

Firstly, linear regression analysis was conducted and listed in Table 2 to reveal independent variable, that is, awareness of service contribute significantly to perceived ease of use $(\beta=0.650, t$-value $=4.289)$. Meaning that users who have a good awareness about the nature of Internet banking are more likely to perceive the ease of using this technology. Further results also show that $\mathrm{SP}(\beta=0.599)$ was statistically significant in the construct of trust.

As stated in the research model, there are more than one variable affecting the dependent variable. Multiple regression therefore is used to analyze the relationship between a single dependent variable and several independent variables (Hair et al., 2011). Table 3 presents the regression analysis output.

The result showed that PEU, QI and TR have a significant effect on perceived usefulness with different degree $(\beta=0.422,0.413,0.392$, respectively). This significance states that users think that's easy to use of Internet banking with a good quality of Internet connection are more likely to accept the system because of the functions it performs. Additionally, it also demonstrates that users who have a trust are likely to have a more positive usefulness of using Internet banking systems. This eventually confirms that Internet banking technologies that are perceived to be less complex and easier to use are more likely of being used by potential and current users.

In the meanwhile, the two TAM beliefs; PU $(\beta=$ $0.429)$ and PEU $(\beta=0.424)$ were found to have positive and significant influence on intention to use Internet banking systems. The significance of PU in this study states that an individual's perceived useful value of using Internet banking. Based on the model analysis, it must be mentioned that the overall model was reasonably fit and statistically significant inferences can be drawn to capture the customers' perception towards the effects of service quality dimensions on the acceptance of Internet banking. Therefore, all hypotheses were accepted. 
Table 1: Demographic characteristics of participants

\begin{tabular}{|c|c|c|c|}
\hline Items & Categories & Frequency & Percent \\
\hline \multirow[t]{3}{*}{ Gender } & Male & 224 & 53 \\
\hline & Female & 201 & 47 \\
\hline & Total & 425 & 100 \\
\hline \multirow[t]{5}{*}{ Age } & $18-25$ & 160 & 38 \\
\hline & $26-35$ & 142 & 33 \\
\hline & $36-45$ & 73 & 17 \\
\hline & Above 45 & 50 & 12 \\
\hline & Total & 425 & 100 \\
\hline \multirow[t]{5}{*}{ Education } & High school & 75 & 18 \\
\hline & Bachelor degree & 227 & 53 \\
\hline & Master degree & 85 & 20 \\
\hline & Doctoral degree & 38 & 9 \\
\hline & Total & 425 & 100 \\
\hline \multirow{5}{*}{ Income } & Less than $500 \mathrm{JD}$ & 161 & 38 \\
\hline & 500-1000JD & 192 & 45 \\
\hline & $1000-2000 \mathrm{JD}$ & 51 & 12 \\
\hline & Above 2000JD & 21 & 5 \\
\hline & Total & 425 & 100 \\
\hline \multirow[t]{3}{*}{ Have you ever used the Internet before? } & Yes & 425 & 100 \\
\hline & No & - & - \\
\hline & Total & 425 & 100 \\
\hline \multirow[t]{4}{*}{ How many years you have been using the Internet? } & $<1$ & - & - \\
\hline & $1-4$ & 3 & 1 \\
\hline & $\geq 5$ & 422 & 99 \\
\hline & $\overline{\text { Total }}$ & 425 & 100 \\
\hline \multirow[t]{3}{*}{ Where do you use the Internet from? } & At home & 238 & 56 \\
\hline & At workplace & 187 & 44 \\
\hline & Total & 425 & 100 \\
\hline \multirow[t]{3}{*}{ Have you ever used Internet banking system before? } & Yes & 425 & 100 \\
\hline & No & - & - \\
\hline & Total & 425 & 100 \\
\hline
\end{tabular}

Table 2: Linear regression analysis

\begin{tabular}{llllll}
\hline Path coefficients in the theoretical model & $\mathrm{t}$-value & Beta coefficient & $R^{2}$ & Sig. & Hypothesis \\
\hline $\mathrm{AW} \rightarrow \mathrm{PEU}$ & 4.289 & 0.650 & 0.422 & 0.000 & Supported \\
$\mathrm{SP} \rightarrow \mathrm{TR}$ & 4.989 & 0.599 & 0.358 & 0.001 & Supported
\end{tabular}
$\mathrm{p} \leq 0.05$

Table 3: Multiple regression analysis

\begin{tabular}{llllll}
\hline Path coefficients in the theoretical model & t-value & Beta coefficient & $R^{2}$ & Sig. & Hypothesis \\
\hline PEU $\rightarrow$ PU & 7.958 & 0.422 & 0.598 & 0.001 & Supported \\
TR $\rightarrow$ PU & 9.437 & 0.392 & & 0.000 & Supported \\
QI $\rightarrow$ PU & 9.214 & 0.413 & & 0.001 & Supported \\
PEU $\rightarrow$ IU & 8.476 & 0.424 & 0.604 & 0.001 & Supported \\
PU $\rightarrow$ IU & 9.968 & 0.429 & & 0.001 & Supported \\
\hline
\end{tabular}

$\mathrm{p} \leq 0.05$

\section{Conclusion and Recommendation}

The study validates the constructs of TAM that are used in many studies in developed countries with a little variation, by using it in a different context. Further, the study successfully confirms the applicability of extension TAM in the Arab world, specifically in Jordanian context to evaluate the direct effects of service quality dimensions on the acceptance of the Internet banking practice.
Generally, the unique environment in which data was collected affects the theoretical framework for this study. So that, the author assigns the extension TAM to understand the user behavior across a broad range of technology users as through of explaining the relationship between different explanatory variables. The analysis presented here is based on a sample of respondents and considers the impact of all mentioned dimensions of service quality variables such as (TR, SP, QI, AW) on the behavioral intention to accept use the 
Internet banking systems. A regression analysis has been used to pinpoint the determinants of the acceptance status based on the responses of the survey.

The study show that the most effective challenges include: Security and privacy within the hypothesis and that $R^{2}$ equals $35.8 \%$ in this research model for using Internet banking systems. For security enhancements, banks may enhance online services to their customers with add-on security procedures or means for reducing perceived risk, as it clarified in section 3.2. Trust building strategies could be developed by bank managers to reduce uncertainty involved in Internet banking system. For instance, money refund guarantees in case of fraud have also shown themselves to be a strong generator of trust. In this sense, a high standard of security and privacy systems are likely to increase trust users in using the Internet banking system. The issue of security and privacy therefore are a continuous challenge in the banking sectors.

In the end, perceived usefulness (PU) is recognized as the most powerful factor among all other variables in shaping the users' intentions to perform online banking transactions. It has been documented that a high level of perceived security in the digital environment is fundamental to foster further acceptance of Internet banking. Notably, since customer trust is hard to obtain and easy to lose, Banks should strive to maintain these dimensions were mentioned in this study to provide Internet banking in a proactive manner.

The implication of this study can be abridged as follows. First, this study proposed a framework based on an extension of (TAM) model in one of developing countries; namely Jordan. This framework can be used to predict the behavioral intention to use banking information system based on service quality dimensions towards a better understanding of banking services progression and introduce several improvements in the future. Moreover, this study contributes to the efforts to empirically validate TAM in the Arab world to raise the contribution of literature in human interaction with online systems.

This study is not free of limitations. First, the research framework was designed to be used and tested with Internet banking settings. Further studies could replicate this study in other online domains to validate the model across other web-based industries, such as apps of banks on smartphone and e-government system. A cross-sectional design technique is adopted in the study that does not show how the individual's behavior may change over time. Future studies therefore could focus on longitudinal research that could be more suitable in predicting behavior over time and hence facilitating comprehensive understanding of the relationships between variables.
To conclude, the study explores that individuals who are better educated and more familiar with the Internet are indeed more positively inclined towards using Internet banking. Consequently, the banking industry is constantly developing and service delivery is still changing. Therefore, in order to be successful, it is important to design a competitive strategy based on service quality and diversity and finding methods of evolving lasting beneficial services and fill gaps between service performance and customer expectations.

\section{Acknowledgment}

Works have been supported by the author himself.

\section{Ethics}

The author confirms that there are no ethical issues involved. This article is original and contains unpublished material.

\section{References}

Adams, D.A., R.R. Nelson and P.A. Todd, 1992. Perceived usefulness, ease of use and usage of information technology: A replication. MIS Quarterly, 16: 227-247. DOI: 10.2307/249577

Agarwal, R. and J. Prasad, 1999. Are individual differences germane to the acceptance of new information technologies. Dec. Sci., 30: 361-391. DOI: $10.1111 /$ j.1540-5915.1999.tb01614.x

Ajzen, I. and M. Fishbein, 1980. Understanding Attitudes and Predicting Social Behavior. 1st Edn., Prentice-Hall, Englewood Cliffs, ISBN-10: 0139364439, pp: 278.

Al-Somali, S.A., R, Gholami and B. Clegg, 2009. An Investigation into the acceptance of online banking in Saudi Arabia. Technovation, 29: 130-141. DOI: 10.1016/j.technovation.2008.07.004

Bitner, M.J., S.W. Brown and M.L. Meuter, 2000. Technology infusion in service encounters. J. Acad. Market. Sci., 28: 138-149. DOI: $10.1177 / 0092070300281013$

Bruno, M.A., 2003. BofA's climb to the top of the online world. US Banker, 113: 24-5.

Coldwell, D. and F. Herbst, 2004. Business Research. 1st Edn., Cape Town, South Africa.

Davis, F.D., 1989. Perceived usefulness, perceived ease of use and user acceptance of information technology. MIS Quarterly, 13: 319-340. DOI: $10.2307 / 249008$.

Doll, W.J. and G. Torkzadeh, 1988. The measurement of end-user computing satisfaction. MIS Quarterly, 12: 259-274. DOI: $10.2307 / 248851$.

Frazer, L. and M. Lawley, 2000. Questionnaire Design and administration: A Practical Guide. John Wiley and Sons, New York, ISBN-10: 0471342920, pp: 119. 
Gefen, D., E. Karahanna and D.W. Straub., 2003. Trust and TAM in online shopping: An integrated mode. MIS Quarterly, 7: 51-90. DOI: 10.2307/30036519

Grewal, D.I., R. Gopalkrishnan and M. Levy, 2004. Internet retailing: enablers, limiters and market consequences. J. Bus. Res., 57: 703-713. DOI: 10.1016/S0148-2963(02)00348-X

Gumussoy, C.A. and F. Calisir, 2009. Understanding factors affecting e-reverse auction use: An integrative approach. Comput. Human Behav., 25: 975-988. DOI: 10.1016/j.chb.2009.04.006

Guriting, P. and N.O. Ndubisi, 2006. Borneo online banking: evaluating customer perceptions and behavioural intention. Manage. Res. News, 29: 6-15. DOI: 10.1108/01409170610645402

Hair, J.F., W.C. Black, B. Babin, R.E. Anderson and R.L. Tatham, 2011. Multivariate Data Analysis. 1st Edn., Prentice Hall, Upper Saddle River, NJ.

IWS, 2017. World internet usage and population statistics.

Jarvenpaa, S.L., N. Tractinsky and M. Vitale, 2000, Consumer trust in an internet store. Inform. Technol. Manage., 1: 45-71. DOI: 10.1023/A:1019104520776

Jaruwachirathanakul, B. and D. Fink, 2015. Internet banking adoption strategies for a developing country: The case of Thailand. Internet Res., 15: 295-311. DOI: 10.1108/10662240510602708

Khalil, M.N. and J.M. Pearson, 2007. The influence of trust on internet banking acceptance. J. Internet Bank. Commerce, 12: 1-11.

Kim, Y.H. and D.J. Kim, 2005. A study of online transaction self-efficacy, consumer trust and uncertainty reduction in electronic commerce transaction. Proceedings of the 38th Hawaii International Conference on System Sciences, Jun. 6-6, IEEE Xplore Press, Big Island, HI, USA, pp: 170c-170c. DOI: 10.1109/HICSS.2005.52

Kimery, M.K. and M. McCord, 2006. Signals of trustworthiness in e-commerce: consumer understanding of third-party assurance seals. J. Electronic Commerce Organiz., 4: 52-73. DOI: $10.4018 /$ jeco. 2006100103

Kristensen, K. and J. Eskildsen, 2010. Design of PLSBased Satisfaction Studies. In: Handbook of Partial Least Squares, Esposito, V., W.W. Chin, J. Henseler and H. Wang, (Eds.), Springer Handbooks of Computational Statistics, Heidelberg, pp: 247-277.

Kuisma, T., T. Laukkanen and M. Hiltunen, 2007. Mapping the reasons for resistance to internet banking: A means-end approach. Int. J. Inform. Manage., 27: 75-85.

DOI: 10.1016/j.ijinfomgt.2006.08.006

Khrais, L.T. and G.M. Abdalkrim, 2013. The Impact of Strategic planning on online banking an empirical study in (Saudi environment). Am. J. Bus. Manage., 2: 53-58. DOI: 10.11634/216796061302293
Laith, T.K., 2015. Highlighting the vunlarabilites of online banking systems. J. Internet Bank. Commerce, 20: 53-78.

Laith, T.K., 2017. Framework for measuring the convenience of advanced technology on user perceptions of Internet banking systems. J. Internet Bank. Commerce, 22: 175-193.

Laukkanen, T., S. Sinkaunen and P. Laukkanen, 2009. Communication strategies to overcome functional and psychological resistance to internet banking. Int. J. Inform. Manage., 29: 111-118. DOI: $10.1016 /$ j.ijinfomgt.2008.05.008

Lee, M., 2009. Factors influencing the adoption of internet banking: An integration of TAM and TPB with perceived risk and perceived benefit. J. Electronic Commerce Res. Applic., 8: 130-141. DOI: $10.1016 /$ j.elerap.2008.11.006

Mathieson, 1991. Predicting user intentions: Comparing the technology acceptance model with the theory of planned behavior. Inform. Syst. Res., 2: 173-191.

McKnight, D.H., C.J. Kacmar and V. Choudhury, 2004. Shifting factors and the ineffectiveness of third party assurance seals: A two-stage model of initial trust in a web business. Electronic Markets, 14: 252-266.

Moon, J.W. and Y.G. Kim, 2001. Extending the TAM for a world-wide-web context. Inform. Manage., 38: 217-230. DOI: 10.1016/S0378-7206(00)00061-6

Mukhtar, M., 2015. Perceptions of UK based customers toward internet banking in the United Kingdom. J. Internet Bank. Commerce, 20: 1-38.

Mzoughi, N., K. Garrouch, O. Bouhlel and A. Negra, 2007. Online procrastination: A predictive model. J. Internet Bus.

Natarajan, T., S.A. Balasubrmanian and S. Manickavasagam, 2010. Customer's choice amongst Self Service Technology (SST) channels in retail banking: A study using Analytical Hierarchy Process (AHP). J. Internet Bank. Commerce, 15: 1-16.

Ndubisi, N.O., R. Supinah and P. Guriting, 2004. The extended technology acceptance model and internet banking usage intention. Proceedings of the International Logistics Congress Proceeding, (LCP' 04), Turkey, December, pp: 973-988.

O'Cass, A. and T. Fenech, 2003. Web retailing adoption: exploring the nature of internet users Web retailing behavior. J. Retail. Consumer Serv., 10: 81-94. DOI: 10.1016/S0969-6989(02)00004-8

Polasik, M. and T.P. Wisniewski, 2009. Empirical analysis of internet banking adoption in Poland. Int. J. Bank Market., 27: 32-52. DOI: $10.1108 / 02652320910928227$

Polatoglu, V.N. and S. Ekin, 2001. An empirical investigation of the Turkish consumers' acceptance of Internet banking services. Int. J. Bank Market., 19: 156-165. DOI: 10.1108/02652320110392527 
Poon, W.C., 2008. Users' adoption of e-banking services: The Malaysian perspective. J. Bus. Indust. Market., 23: 59-69.

DOI: $10.1108 / 08858620810841498$

Quelch, J.A. and L.R. Klein, 1996. The internet and international marketing. Sloan Manage. Rev., 37: 60-75.

Reichheld, F.F. and P. Schefter, 2000. E-loyalty: your secret weapon on the web. Harvard Bus. Rev., 78: 105-113.

Rogers, E., 1993. Diffusion of Innovation. 1st Edn., The Free Press, New York.

Saleh and Steve, 2014. Using the technology acceptance model in understanding academics' behavioral intention to use learning management systems. Int. J. Adv. Comput. Sci. Applic., 5: 220-233.

Sathye, M., 1999. Adoption of Internet banking by Australian consumers: An empirical investigation. Int. J. Bank Market., 17: 324-334. DOI: $10.1108 / 02652329910305689$

Sekaran, U., 2000. Research Methods for Business: A Skill Building Approach. 1st Edn., John Wiley and Sons.

Shih, H., 2004. An empirical study on predicting user acceptance of e-shopping on the web. Inform. Manage., 41: 351-368.

DOI: $10.1016 / \mathrm{S} 0378-7206(03) 00079-\mathrm{X}$

Stewart, K.J., 2003. Trust transfer on the World Wide Web. Organiz. Sci., 14: 5-17.

DOI: $10.1287 /$ orsc. 14.1.5.12810
Tan, M. and T.S.H. Teo, 2000. Factors influencing the adoption of Internet banking. J. Assoc. Inform. Syst., 1: 1-42. DOI: 10.1016/j.elerap.2008.11.006

Taylor, S., Todd, P., 1995, Decomposition and crossover effects in the theory of planned behavior: A study of consumer adoption intentions. Int. J. Res. Market., 12: 137-155. DOI: 10.1016/0167-8116(94)00019-K

Thompson, R.L. C.A. Higgins and J.M. Howell, 1991. Personal computing: Toward a conceptual model of utilization. MIS Quarterly, 15: 125-143. DOI: $10.2307 / 249443$

Venkatesh, V. and F.D. Davis, 2000. A theoretical extension of the technology acceptance model: Four longitudinal field studies. Manage. Sci., 46: 186-205. DOI: $10.1287 / \mathrm{mnsc} .46 .2 .186 .11926$

Wakefield, R.L. and D. Whitten, 2006. Examining user perceptions of third-party organizations credibility and trust in an e-retailer. J. Organiz. End User Comput., 18: 1-19. DOI: 10.4018/joeuc.2006040101

Wang, Y.S., Y.M. Wang, H.H. Lin and T.I. Tang, 2003. Determinants of user acceptance of Internet banking: An empirical study. Int. J. Service Industry Manage., 14: 501-519.

DOI: $10.1108 / 09564230310500192$

Zikmund, W.G., 2003. Business Research Methods. 8th Edn., Thom-son/South-Western, Cincinnati, Ohio. 